\title{
Low cost carbon electrodes to produce salinity gradient energy using reverse electrodialysis membranes: Effect of feed flow velocities and addition of $\mathbf{M g}^{2+}$
}

\author{
Tsalis Wahyu Najmiyah ${ }^{1}$, Lina Aziyah ${ }^{1}$, Yusuf Hendrawan $^{2}$, Dewi Maya Maharani ${ }^{2}$, La Choviya Hawa ${ }^{2}$, and Yusuf \\ Wibisono $^{1,3^{*}}$
}

${ }^{1}$ Universitas Brawijaya, Bioprocess Engineering, Jl. Veteran 1, Malang 65145, Indonesia

${ }^{2}$ Universitas Brawijaya, Agriculture Engineering, Jl. Veteran 1, Malang 65145, Indonesia

${ }^{3}$ MILI Institute for Water Research, PO Box 301 ML, Malang 65101, Indonesia

\begin{abstract}
In this research, we investigate the effect of feed flow velocity in both monovalent $\left(\mathrm{Na}^{+}\right)$and divalent $\left(\mathrm{Mg}^{2+}\right)$ salt water solutions to harvest the electrical energy from the reverse electro dialysis (RED) membranes module. The synthetic sea water solution uses $0.5 \mathrm{M}$ concentration of salt and the synthetic river water salt concentration of $0.017 \mathrm{M}$ were used. The carbon electrode was used, due to its low cost, higher melting point, and insoluble in water. Variation of feed flow velocities (sea water and synthetic river water) of $8 \mathrm{~cm}^{2} / \mathrm{s}, 14 \mathrm{~cm}^{2} / \mathrm{s}, 19 \mathrm{~cm}^{2} / \mathrm{s}$ were used, in addition to compare electrical energy produced from the used of monovalent and divalent ions. The best result was obtained by using the velocity of feed solution 19 $\mathrm{cm}^{2} / \mathrm{s}$ with the electricty value of $8.033 \mathrm{mV}, 0.002 \Omega / \mathrm{cm}^{2}$ and power density of $1,141 \mathrm{~mW} / \mathrm{m} 2$, while the influence of the addition of $\mathrm{Mg}^{2}{ }^{+}$ion in the feed solution resulted the electricty value of $4.47 \mathrm{mV}, 0.003$ $\Omega / \mathrm{cm}^{2}$ and power density of $0.15 \mathrm{~mW} / \mathrm{m}^{2}$. Albeit the results, some more configuration is needed and worth to be investigated in the future.
\end{abstract}

\section{Introduction}

Recently, electricity becomes a major necessity in human life. Total electrical energy requirement was significantly enhanced, due to growth of population and industrial development. In Indonesia, most electricity generated by power plants is using petroleum as major fuel [1]. The use of fossil fuel is not only required higher cost, but also is not a sustainable energy generation [2].

On the other hand, Indonesia has abundance sea and river water, and its could potentially used for energy generation. Membrane technology could help to generate new energy sources and conversion [3, 4]. Reverse electrodialysis (RED) could turns sea water and river water into electricity by capturing energy when mixing the water due to their salinity gradients. By using selective membranes i.e. cation exchange membranes (CEM) and anion exchange membranes (AEM), the salinity gradients from mixture of sea water and river water might induce electrochemical difference potential to be used as electricity source [5].

The difference in charge between the membranes might attract $\mathrm{Cl}^{-}$ions from $\mathrm{NaCl}$ compounds of seawater to the anode and lead to oxidation reaction. Meanwhile, $\mathrm{Na}^{+}$ions will be attracted to cathode and lead to reduction reaction. The electrical current or voltage will be induced by CEM and AEM selective membranes due to Donnan potential between the interface of membranes and water. Furthermore, it can be converted into a electrical current by placing two electrodes on the outer side of membranes. It is due to a redox reaction that converts ion flow into an electrical current [6].

This study is aiming at the effect of feed velocities and the presence of of divalent ions such as $\mathrm{MgCl}_{2}$ in feed to RED performance e.g. voltage (OCV), stack resistance, and power density. It should be noted that sea water have different characteristics. Sea water not only contains $\mathrm{NaCl}$ salt, but can also contain $\mathrm{MgCl}_{2}$ mixtures. However, the presence of $\mathrm{Mg}^{2+}$ ions will result in higher resistance and voltage (OCV) output will decrease [7]. The lower valence of solution that fed into system, the voltage produced will be increased [8]. Moreover, this study also utilized graphite (carbon) as low cost electrodes. The results obtained will be compared to previous studies.

\section{Experiment}

\subsection{Materials}

The materials used in this study are $0.5 \mathrm{M}$ synthetic seawater and $0.017 \mathrm{M}$ synthetic river water with different $\mathrm{NaCl}: \mathrm{MgCl}_{2}$ ratio of 100:0; 90:10; 80:20; and 70:30. The use of synthetic solutions with different salt concentration was aiming at the lower concentration of salt solution and makes $\mathrm{Na}^{+}, \mathrm{Mg}^{2+}$ and $\mathrm{Cl}^{-}$ions can migrate easily in water.

* Corresponding author: y_wibisono@ub.ac.id 
CEM membranes (FKS-15) and AEM membranes (FAS-15) with size $(10 \times 12) \mathrm{cm}^{2}$ and spacer ED-100, were purchased from Fumatech, Germany. Spacers has an important effect on fluid dynamics in the membrane modules $[9,10]$. Furthermore, $0.05 \mathrm{FeCl}_{3}$ and $\mathrm{NaCl} 0.25$ $\mathrm{M}$ were used as electrolyte solution and carbon graphite of $16 \times 16 \mathrm{~cm}^{2}$ was used as electrodes.

The used of graphite (carbon) as an electrode has an advantages, i.e. this material is cheaper than others. However, the carbon also has electrical current deficiency. The wider surface of graphite can disrupt collection of electrical current. The problem with graphite electrode can be overcome by using a combination of graphite electrodes with homogeneous redox reactions such as $\mathrm{Fe}^{2+} / \mathrm{Fe}^{3+}[6]$.

A customized laboratory scale RED module was designed and manufactured in local workshop. The module is only used a single stack module, consist of one sheet AEM and two sheets CEM. The schematic arrangement and flow configuration of RED module used in this study is shown in Figure 1.

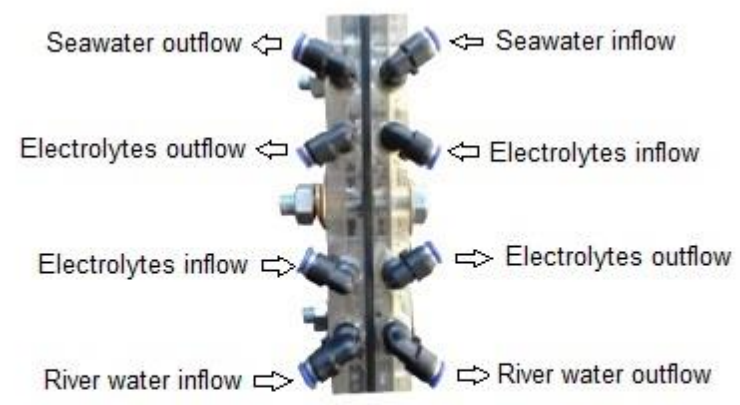

(a)

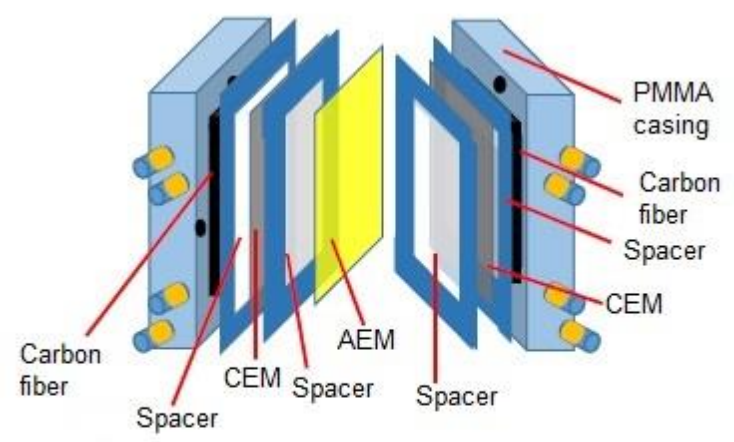

(b)

Fig. 1. (a) Flow configuration, and (b) RED stack.

\subsection{Method}

Synthetic seawater was prepared from $0.5 \mathrm{M}$ $\mathrm{NaCl}: \mathrm{MgCl}_{2}$ solutions with different ratios of 100:0; $90: 10 ; 80: 20$; and 70:30 and dissolved in $1 \mathrm{~L}$ demineralized water. Synthetic river water was prepared from $0.017 \mathrm{M} \mathrm{NaCl}: \mathrm{MgCl}_{2}$ solutions with different ratios of 100: $0 ; 90: 10 ; 80: 20$; and 70:30 and dissolved in $1 \mathrm{~L}$ demineralized water. Seawater and river water composition used in this study is summarized in Table $\mathbf{1 .}$
Table 1. Composition of $\mathrm{NaCl}: \mathrm{MgCl}_{2}$.

\begin{tabular}{|c|c|}
\hline $\begin{array}{c}\text { Sea water } \\
\text { composition }\end{array}$ & $\begin{array}{c}\text { River water } \\
\text { composition }\end{array}$ \\
\hline $0.5 \mathrm{M} \mathrm{NaCl}$ & $0.0017 \mathrm{M} \mathrm{NaCl}$ \\
\hline $0.45 \mathrm{M} \mathrm{NaCl}+$ & $0.0153 \mathrm{M} \mathrm{NaCl}+$ \\
$0.05 \mathrm{M} \mathrm{MgCl}{ }_{2}$ & $0.0017 \mathrm{M} \mathrm{MgCl}{ }_{2}$ \\
\hline $0.40 \mathrm{M} \mathrm{NaCl}+$ & $0.0136 \mathrm{M} \mathrm{NaCl}+$ \\
$0.1 \mathrm{M} \mathrm{MgCl}$ & \\
\hline $0.35 \mathrm{M} \mathrm{NaCl}+$ & $0.0034 \mathrm{M} \mathrm{MgCl}_{2}$ \\
$0.15 \mathrm{M} \mathrm{MgCl}_{2}$ & $0.0119 \mathrm{M} \mathrm{NaCl}^{2}$ \\
& $0.0051 \mathrm{M} \mathrm{MgCl}_{2}$ \\
\hline
\end{tabular}

Furthermore, electrolytes solutions was prepared from $0.25 \mathrm{M} \mathrm{NaCl}$ and $0.05 \mathrm{M} \mathrm{FeCl}_{3}$ and dissolved in 500 $\mathrm{mL}$ demineralized water. Each mixture was then injected into RED stack as schematically shown in Figure 1.

The seawater and riverwater flow velocities were fixed at 8,14 and $19 \mathrm{~cm}^{3} / \mathrm{s}$. The energy yield from different of salt ratio $\mathrm{NaCl}: \mathrm{MgCl}_{2}$ harvested using carbon electrons and measured using a multimeter for 20 seconds. The open circuit voltage (OCV), the resistance were measured; then the power density was calculated by using the following formulas:

$$
\begin{aligned}
& O C V_{\text {theoritic }}=2 N \frac{\alpha R T}{Z F} \ln \frac{a_{s}}{a_{r}} \\
& R_{\text {stack }}=\frac{R}{A} \\
& \alpha=\frac{O C V_{\text {measured }}}{O C V_{\text {theoritic }}} \times 100 \% \\
& P D=\frac{O C V^{2}}{4 x R_{\text {stack }}}
\end{aligned}
$$

where:

$\mathrm{OCV}$, voltage $(\mathrm{mV})$

$R$, gas contant $(8,314 \mathrm{~J} /(\mathrm{mol} \mathrm{K}))$

$T$, temperature (K)

$\alpha$, membrane permselectivity ( $\%$ )

$\mathrm{N}$, amount of cell membranes

A, membrane area

$F$, Faraday constant $(96485 \mathrm{C} / \mathrm{mol})$

$\mathrm{Z}$, salt charge

$\alpha_{\mathrm{S}}$, molarity of seawater salt $(\mathrm{mol} / \mathrm{l})$

$\alpha r$, molarity of river water salt $(\mathrm{mol} / \mathrm{l})$

$\mathrm{R}_{\text {stack, }}$ stack resistance $\left(\Omega / \mathrm{cm}^{2}\right)$

$\mathrm{PD}$, power density $\left(\mathrm{mW} / \mathrm{m}^{2}\right)$

\section{Results and discussion}

\subsection{Open Circuit Voltage (OCV)}

The effect of $\mathrm{MgCl}_{2}$ concentration on $\mathrm{OCV}$ value is presented in Figure 2. As shown, the highest OCV value with addition of $\mathrm{MgCl}_{2}$ is produced by $\mathrm{NaCl}: \mathrm{MgCl}_{2}$ ratio of $90: 10$ with feed velocity of $19 \mathrm{~cm}^{3} / \mathrm{s}$ with a value of $4.47 \mathrm{mV}$. It can be concluded that lower concentration of 
$\mathrm{MgCl}_{2}$ and higher feed velocity which were fed into RED system, might increase OCV value.

The results inline with the results of Gilstrap, et al. [8] which states that the more ratio of salt concentrations containing monovalent ions on the RED membrane, the greater OCV value. A low feed velocity results the OCV value of $8.03 \mathrm{mV}$, much lower than study of Vermaas et al. [5] which was produced about $61 \mathrm{mV}$ in single RED cell. The higher results was due to the use of $\mathrm{Ti}$ electrode, thats has higher electrical conductivity compared to carbon.

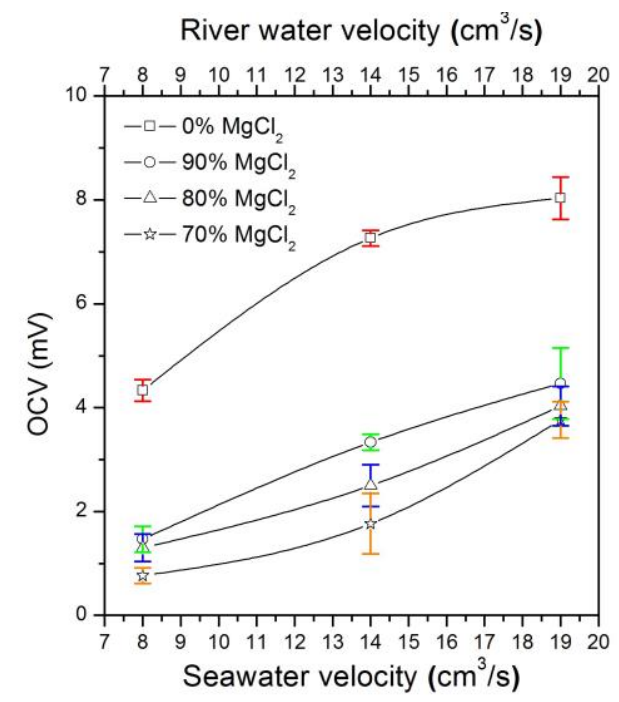

Fig. 2. Effect of $\mathrm{NaCl}_{\mathrm{MgCl}}$ salts ratio to $\mathrm{OCV}$.

Figure 3 shows feed velocities relation to OCV. It is clear that the highest OCV value of $8.033 \mathrm{mV}$ obtained from both seawater and river water velocities of 19 $\mathrm{cm}^{3} / \mathrm{s}$. The same trend was found in the previous study [8].

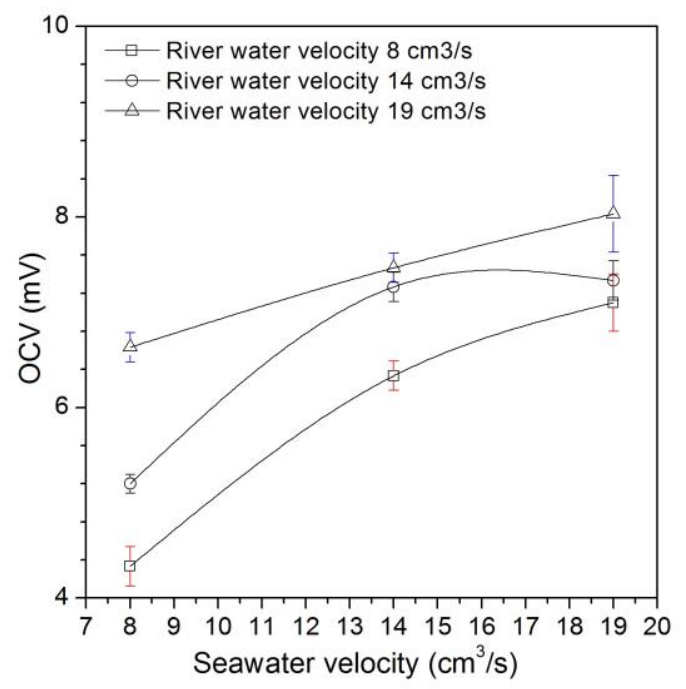

Fig. 3. Effect of feed velocities to OCV.

\subsection{Stack resistance}

The effect of $\mathrm{NaCl}: \mathrm{MgCl}_{2}$ ratio to $\mathrm{RED}$ stack resistance is shown in Figure 4. As shown, the stack resistance is inversely the voltage results. By increasing feed velocity up to $19 \mathrm{~cm}^{3} / \mathrm{s}$ and the least $\mathrm{MgCl}_{2}$ concentration, the stack resistance reached as low as $0.003 \Omega / \mathrm{cm}^{2}$. The addition of $\mathrm{MgCl}_{2}$ could decrease the permselectivity on FKS-15 and FAS-15 membranes.

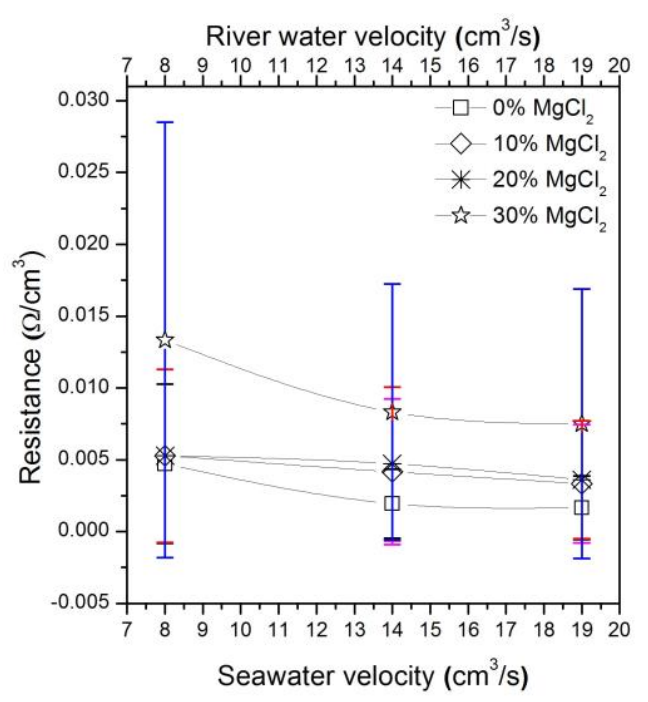

Fig. 4. Effect of $\mathrm{NaCl}: \mathrm{MgCl}_{2}$ ratio to stack resistance.

While, higher feed velocities of $19 \mathrm{~cm}^{3} / \mathrm{s}$ could decreased the RED stack resistance until the value of $0.002 \Omega / \mathrm{cm}^{2}$. This trend is shown in Figure 5 .

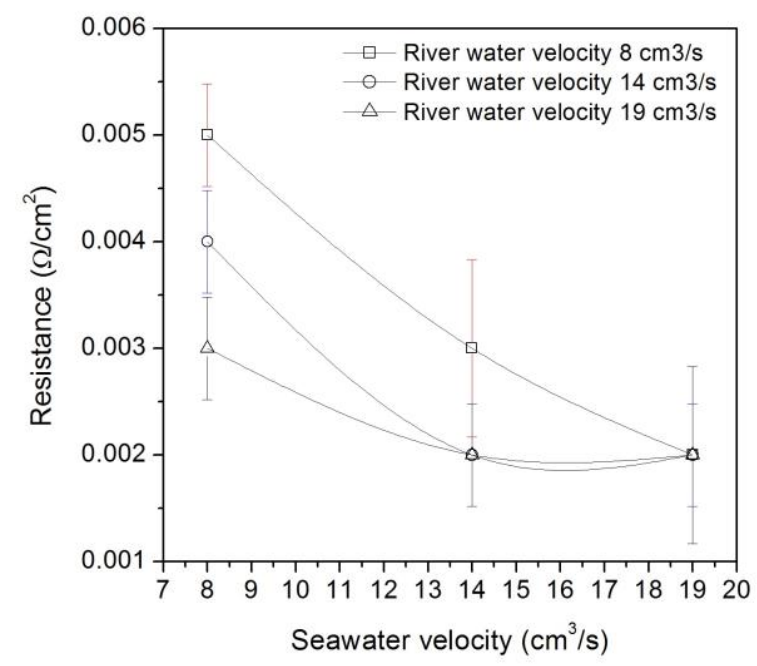

Fig. 5. Effect of feed velocities to stack resistance.

\subsection{Power density}

The effect of $\mathrm{NaCl}: \mathrm{MgCl}_{2}$ salts ratio to power density is shown in Figure 6. As shown, the highest values of power density of $0.15 \mathrm{~mW} / \mathrm{m}^{2}$ is obtained in $\mathrm{NaCl}: \mathrm{MgCl}_{2}$ (90:10) mixing with velocity of $19 \mathrm{~cm}^{3} / \mathrm{s}$. The use of pure $\mathrm{NaCl}$ solution even provide the significant increase of power density up to $1.14 \mathrm{~mW} / \mathrm{m}^{2}$. The increase power 
density value is due to the chemical potential difference between two salt solution mixtures. The increase of chemical potential is due to increase of ionic quantities that move from synthetic seawater salt solution to synthetic river water salt solution.

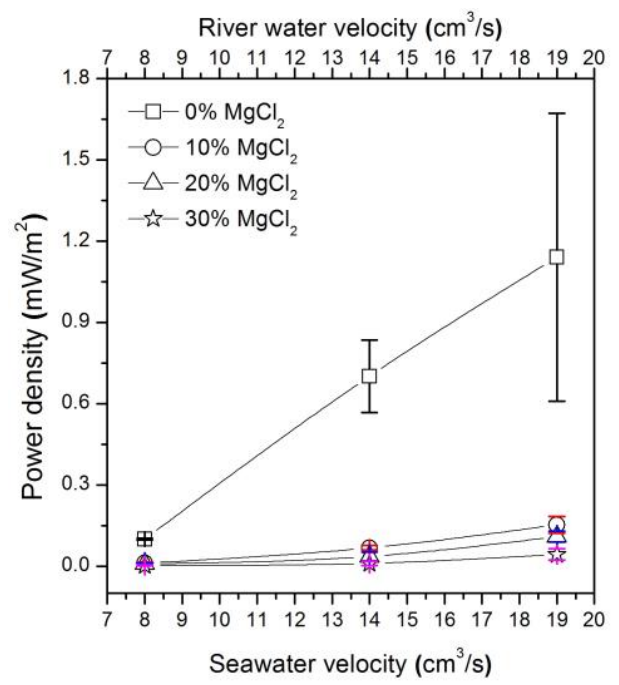

Fig. 6. Effect of $\mathrm{NaCl}: \mathrm{MgCl}_{2}$ salts ratio to power density.

As the effect of feed velocity is also comparable with previous results, the higher feed velocities can increase the power density. Figure 7 shows the details. This is consistent with previous studies that the increasing of feed flow velocity of both types of salt solution will maximize the rate of ion transfer to electrode. Moreover, the power density obtained will also increase.

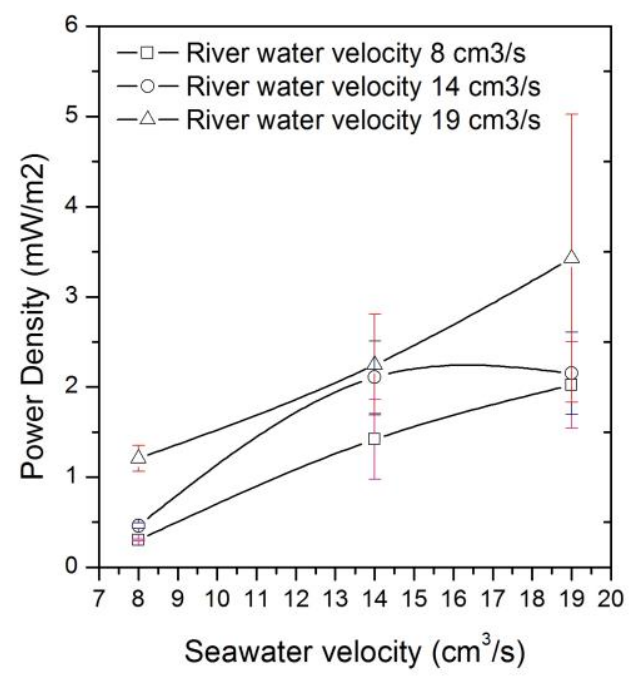

Fig. 7. Effect of feed velocities to power density.

\section{Conclusions}

The highest OCV value, lowest stack resistance and higher power density obtained from higher feed flow velocities of seawater $19 \mathrm{~cm}^{2} / \mathrm{s}$ and river water of 19 $\mathrm{cm}^{2} / \mathrm{s}$, with the OCV value of $8033 \mathrm{mV}$, stack resistance of $0.002 \Omega / \mathrm{cm}^{2}$, and power density of $1.141 \mathrm{~mW} / \mathrm{m}^{2}$, respectively. On the other hand, the addition of $\mathrm{MgCl}_{2}$ provide inversely different results.

\section{References}

1. B.M. Sopha, A.R. Pamungkas, AIP Conference Proceedings (2016)

2. W.A. Nugroho, R. Nugraha, Y. Wibisono, Proceeding of Sharia Economics ConferenceHannover (2013)

3. L.A. Devianto et al. IOP Conference Series: Earth and Environmental Science (2018)

4. Y. Wibisono, W.A. Nugroho, T.-W. Chung, Procedia Chemistry 9, 210 (2014)

5. D. Vermaas, Dissertation, University of Twente (2014)

6. J. Veerman, M. Saakes, S.J. Metz, G.J. Harmsen, Journal of Applied Electrochemistry 40, 1461 (2010)

7. A.H. Avci et al. Journal of Membrane Science 520, 499 (2016)

8. M.C. Gilstrap, Dissertation, Georgia Institute of Technology (2013)

9. Y. Wibisono, F. Ahmad, E.R. Cornelissen, A.J.B. Kemperman, K. Nijmeijer, Desalination and Water Treatment 57, 17625 (2016)

10. Y. Wibisono, E.R. Cornelissen, A.J.B. Kemperman, D.C. Nijmeijer, W.G.J. Van Der Meer, Procedia Engineering (2012) 